\title{
The Asymmetric Effect of News on Tehran Stock Exchange Volatility
}

\author{
E. Abounoori and Y. Nademi
}

\begin{abstract}
This paper uses daily data from the Tehran stock exchange (TSE) to illustrate the nature of stock market volatility in an emerging stock market. Most studies suggest that a negative shock to stock prices will generate more volatility than a positive shock of equal magnitude. In this paper we have estimated GJR models with both Gaussian innovations and fat-tailed distributions, such as the Student's $t$ and the GED. Results indicate that leverage effect exists in Tehran Stock Exchange, because in GJR models with t-student and GED distributions, the effects of bad news on volatility $(\alpha 1)$ is larger than the effects of good news on volatility $(\lambda)$. P-Value LR Test for Leverage Effect in Table 2 indicates that the differences between the $\alpha 1$ and $\lambda$ coefficients is not significant for GJR-N model but it is significant at $5 \%$ confidence level for GJR models with $\mathbf{t}$ student and GED distributions.
\end{abstract}

Index Terms-Asymmetric Effect of News, Leverage Effect, Tehran stock exchange, Volatility

\section{INTRODUCTION}

The volatility of financial markets has been the object of numerous developments and applications over the past two decades, both theoretically and empirically. While most researchers agree that volatility is predictable in many asset markets [2], they differ on how this volatility predictability should be modeled. Over the past several decades the evidence for predictability has led to variety of approaches. The most interesting of these approaches are the "asymmetric" or "leverage" volatility models in which good news and bad news have different predictability for future volatility $[1,2,3,5,7,10,12]$. In most of these studies researchers have documented strong evidence that volatility is asymmetric in equity markets $[4,5,10]$. This paper is organized as follows. In section 2 the GJR models of stock return volatility are outlined. Section 3 describes the data. Section 4 presents empirical results and estimates of the relationship between news and volatility for the selected models. The final section provides a brief summary and conclusion.

\section{GJR MODEL}

The rate of return $r_{t}$ is defined as following:

$$
r_{t}=100\left[\log \left(p_{t}\right)-\log \left(p_{t-1}\right)\right]
$$

Manuscriptt received July 25, 2011; revised August 3, 2011

Esmaiel Abounoori, Professor of Econometrics \& Social Statistics, Department of Economics, University of Mazandaran, Babolsar-Iran. (e.abounoori@umz.ac.ir)

Younes Nademi, Department of Economics, Ayatollah Boroujerdi University, Boroujerd-Iran.. (younesnademi@ut.ac.ir) where $p_{t}$ is daily closing stock market index.

[8] Put forward a modified GARCH model (GJR) to account for the 'leverage effect'. This is an asymmetric GARCH model which allows the conditional variance to respond differently to shocks of either sign and is defined as follows

$$
h_{t}=\alpha_{0}+\alpha_{1} \mathcal{E}_{t-1}^{2}\left[1-I_{\left\{\mathcal{E}_{t-1}>0\right\}}\right]+\lambda \mathcal{E}_{t-1}^{2}\left[I_{\left\{\mathcal{E}_{t-1}>0\right\}}\right]+\beta_{1} h_{t-1}
$$

where $I_{\left\{\varepsilon_{t-1}>0\right\}}$ is the indicator function which is equal to one when $\varepsilon_{t-1}>0$ and zero otherwise. In other words, after a good news $\varepsilon_{t-1}>0$ the coefficient of $\mathcal{E}_{t-1}^{2}$ is $\lambda$ but after a bad news $\left\{\varepsilon_{t-1}<0\right\}$ the coefficient would be $\alpha_{1}$.

Another common finding in the GARCH literature is the leptokurtosis of the empirical distribution of financial returns. To model such fat-tailed distributions, researchers have adopted the Student's t or the Generalized Error Distribution (GED). Therefore, in addition to the classic Gaussian assumption, in what follows, the errors $\left(\varepsilon_{t}\right)$ are also assumed to be distributed according to a Student's t or a GED distribution. If a Student's t distribution with $\boldsymbol{V}$ degrees of freedom is assumed, the probability density function (pdf) of $\left(\varepsilon_{t}\right)$ takes the form

$$
f\left(\varepsilon_{t}\right)=\frac{\Gamma\left(\frac{v+1}{2}\right)}{\sqrt{\pi} \Gamma\left(\frac{v}{2}\right)}(v-2)^{-\frac{1}{2}}\left(h_{t}\right)^{-\frac{1}{2}}\left[1+\frac{\varepsilon_{t}^{2}}{h_{t}(v-2)}\right]^{\frac{(v+1)}{2}}
$$

where $\Gamma($.$) is the complete Gamma function and \boldsymbol{V}$ is the degree-of-freedom (or shape) parameter, constrained to be greater than two so that the second moments exist. With a GED distribution instead, the pdf of the innovations becomes

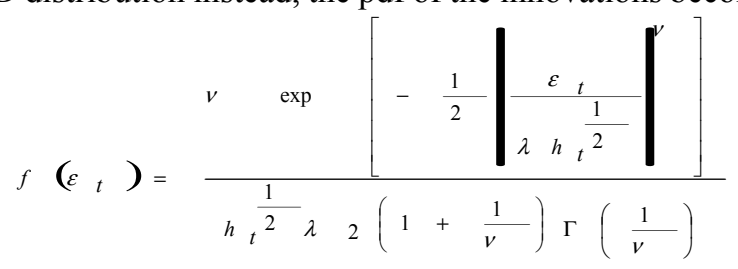

In which

$$
\lambda \equiv\left[\frac{2^{-\frac{2}{v}} \Gamma\left(\frac{1}{v}\right)}{\Gamma\left(\frac{3}{v}\right)}\right]^{\frac{1}{2}}
$$

where $\Gamma($.$) is the Gamma function, v$ is the thickness-of-tail (or shape) parameter satisfying the condition $0<v \leq \infty$ indicating how thick the tails of the distribution are, compared to the normal. When the shape parameter $v=2$, the GED becomes a standard normal distribution, while for 
$v<2$ and $v>2$ the distribution has thicker and thinner tails than the normal, respectively.

To estimate the model, we follow the quasi-maximum likelihood. Both the conditional mean and the conditional variance are estimated jointly by maximizing the log-likelihood function which is computed as the logarithm of the product of the conditional densities of the prediction errors. The ML estimates are obtained by maximizing the log-likelihood with the Broyden, Fletcher, Goldfarb, and Shanno (BFGS) quasi-Newton optimization algorithm in the MATLAB numerical optimization routines.

\section{DATA DESCRIPTION}

The TSE opened officially in February 1967 with only six listed companies compared to the 420 companies that individual and institutional investor trade today. The first ten years of the TSE was marked by a brisk activity where capitalization rose from IRR 6.2 billion to IRR 240 billion and the listed companies grew to 105. After 1978, the Islamic revolution and Iraq's invasion to Iran reduced exchange activities significantly and capitalization fell again to IRR 9.9 billion in 1982. After the Iraq-Iran war ended, the TSE was perceived as one of the most important mechanisms to foster economic development by channeling savings into investment. This goal quickly accelerated the number of listed companies from 56 in 1988 to 422 in 2006.

Between 2000 and 2004, the market capitalization of the TSE grew from IRR 60 billion to IRR 411 billion. The TEPIX index reached an all-time high of 13,882 on August 4, 2004, but within two years, a severe market correction brought the index down 35\% to 9069 on July 26, 2006. The stock market plunge was not all negative because it was perceived as a healthy correction in a market that has run ahead of its fundamentals and needed better controls and improved transparency. In fact, the market correction brought major reforms and led, in particular, to the consolidation and merger of many smaller companies. By 2007, the market capitalization has actually risen above its level in 2004, but the number of listed companies was still low because the merger and acquisition activity remained brisk.

The TSE was not directly affected by the international financial turmoil in 2008, but following the global reduction in prices of copper and steel, the bourse index dropped by 12.5 percent, as most of the companies listed on the exchange are producers of such commodities. TSE experienced an $11 \%$ growth at the end of 2008 and ranked second in the world in terms of increase in the volume of trade after Luxembourg's Bourse. On August 2, 2010, the TSE main index (TEPIX) reached a record level of 16,056 points, despite US-sponsored sanctions against Iran. Thus, TEDPIX became the world's second-best performing equity index. Factors such as the global spike in oil and metal prices, government support for industries and oil sectors as well as the growth of stock market liquidity flow contributed to the boom. the growth was also partly due to a government decision to sell off 20 percent of its equity in two major automakers. Given the relative low market valuation of TSE stocks in 2010, the upward trend was expected to continue over the long run, rather than being a bubble. TEPIX reached a new record on September 18, 2010, when it hit 18,658, up from 11,295 at the start of the year. As of December 2010, the TSE index rose about 64 percent since the start of 2010. The Tehran Stock Exchange has been ranked as the best bourse index in Europe, Africa and Middle East in 2010 in terms of performance of the main index.

Tehran Stock Exchange Characteristics are:

1) Stock prices in the TSE by regulation and intervention cannot exceed from some range.

2) The history of TSE is very short compared to other stock markets.

3) The information flow in this market is very slow.

Trading in Tehran stock exchange (TSE) is based on orders sent by the brokers. Trading days in week are: Saturday, Sunday, Monday, Tuesday, and Wednesday except national holidays. The data consist of 3067 daily observations of the closing value of the TSE from 09/29/1997 to $09 / 09 / 2010$. The return is calculated as $r_{t}=100\left[\log \left(\frac{P_{t}}{P_{t-1}}\right)\right]$ where $P_{t}$ is the index value at time t. Table 1 shows some descriptive statistics of the TSE rate of return. The mean is quite small and the standard deviation is around 0.3 . The Kurtosis $(\mathrm{Ku})$ is significantly higher than the normal value of 3 indicating that fat-tailed distribution are necessary to correctly describe conditional distribution of $r_{t}$ The Scenes (Ski) is significant, small and negative, showing that the lower tail of empirical distribution of the return is longer than the upper tail, that means negative returns are more likely to be far below the mean than their counterparts.

\begin{tabular}{|l|c|c|c|c|c|}
\hline \multirow{2}{*}{ Mean } & $S k$ & $K u$ & $B-J$ & $Q^{2}(12)$ & LM(12) \\
\hline 0.0248 & -0.68 & 71.75 & 654376.1 & 182.89 & 77.05 \\
\hline \multicolumn{7}{|c|}{ p-value: } & {$[0.00]$} & {$[0.00]$} & {$[0.00]$} \\
\hline
\end{tabular}

Note: $\mathrm{Sk}$ and $\mathrm{Ku}$ are skewness and excess kurtosis. B-J is the Bera-Jarque test for normality distributed as $\chi^{2}(2)$. The $Q^{2}(12)$ statistic is the Ljung-Box test on the squared residuals of the conditional mean regression up to the twelfth order. for serial correlation in the squared return data, distributed as $\chi^{2}(12)$. $\quad \mathrm{LM}(12)$ statistic is the ARCH LM test up to twelfth lag and under the null hypothesis of no ARCH effects it has a $\chi^{2}(q)$ distribution.

LM (12) is the Lagrange Multiplier test for ARCH effects in the OLS residuals from the regression of the returns on a constant, while $Q^{2}(12)$ is the corresponding Ljung-Box statistic on the squared standardized residuals. Both these statistic are highly significant suggesting the presence of $\mathrm{ARCH}$ effects in the TSE returns up to the twelfth order.

Table 2 shows some unit root tests for rate of return series. Results indicate that the rate of return series has not unit root. 
So, the rate of return series is a stationary process.

TABLE 2. UNIT ROOT TESTS FOR RATE OF RETURN SERIES

\begin{tabular}{|l|l|l|}
\hline Test Type & $\begin{array}{l}\text { Augmented } \\
\text { Dickey-Fuller }\end{array}$ & Phillips-Perron \\
\hline Statistic & -10.55 & -53.17 \\
\hline P-Value & 0.00 & 0.00 \\
\hline Null Hypothesis & Rate of Return has a unit root \\
\hline
\end{tabular}

\section{EMPIRICAL RESULTS}

The use of a t-distribution instead of a normal one is quite popular in the standard single-regime GARCH literature. For regime switching models, a t-distribution can be more useful. After all, in case of normality, a large innovation in the low-volatility period will lead to a switch to the high-volatility regime, even if it is a single outlier in an otherwise tranquil period. Allowing for a t-distribution will thus enhance the stability of the regimes. Note that the $\mathrm{t}$-distribution includes the normal distribution as the limiting case where the degrees of freedom tend to infinity.

TABLE 3. MAXIMUM LIKELIHOOD ESTIMATES OF GJR MODEL USING DIFFERENT CONDITIONAL DISTRIBUTIONS

\begin{tabular}{|c|c|c|c|}
\hline & GJR-N & GJR-T & GJR-GED \\
\hline p & 0.04074 & 0.0433 & 0.03988 \\
\hline $\mathrm{p}$-value & 0.00 & 0.00 & 0.00 \\
\hline 40 & 0.03943 & 0.02632 & 0.031207 \\
\hline p-value & 0.00 & 0.00 & 0.00 \\
\hline$x_{1}$ & 0.4599 & 0.6166 & 0.57814 \\
\hline $\mathrm{p}$-value & 0.00 & 0.00 & 0.00 \\
\hline$\mu_{1}$ & 0.4862 & 0.7657 & 0.71945 \\
\hline p-value & 0.00 & 0.00 & 0.00 \\
\hline$\lambda$ & 0.4079 & 0.2822 & 0.3079 \\
\hline p-value & 0.00 & 0.00 & 0.00 \\
\hline $\boldsymbol{y}$ & & 3.83 & 0.9488 \\
\hline $\mathrm{p}$-value & & 0.00 & 0.00 \\
\hline $\begin{array}{c}\log \\
\text { likelihood }\end{array}$ & -1281.922 & -838.1431 & -880.0731 \\
\hline $\begin{array}{c}\text { P-Value } \\
\text { LR Test } \\
\text { for } \\
\text { Leverage } \\
\text { Effect }\end{array}$ & 0.21 & 0.00 & 0.00 \\
\hline
\end{tabular}

Based on the "asymmetric" or "leverage" volatility models, good news and bad news have different predictability for future volatility $[1,2,3,5,7,10,12]$. In most of these studies researchers have documented strong evidence that volatility is asymmetric in equity markets: negative returns are generally associated with upward revisions of the conditional volatility while positive returns are associated with smaller upward or even downward revisions of the conditional volatility $[4,5,11]$. Researchers [1, 14] believe that the asymmetry could be due to changes in leverage in response to changes in the value of equity. Others have argued that the asymmetry could arise from the feedback from volatility to stock price when changes in volatility induce changes in risk premiums $[3,6,13]$. The presence of asymmetric volatility is most apparent during a market crisis when large declines in stock prices are associated with a significant increase in market volatility. Asymmetric volatility can potentially explain the negative skewness in stock return data, as discussed in [9]. In this paper, results indicate that leverage effect exists in Tehran Stock Exchange, because in GJR models with t-student and GED distributions, the effects of bad news on volatility $\left(\alpha_{1}\right)$ is larger than the effects of good news on volatility $(\lambda)$. P-Value LR Test for Leverage Effect in Table 2 indicates that the differences between the $\alpha_{1}$ and $\lambda$ coefficients is not significant for GJR-N model but it is significant at 5\% confidence level for GJR models with $\mathrm{t}$ student and GED distributions.

\section{CONCLUSION}

In this paper we have estimated GJR models with both Gaussian innovations and fat-tailed distributions, such as the Student's t and the GED. Results indicate that leverage effect exists in Tehran stock exchange. In other words, the effect of bad news on volatility is larger than that of the good news on volatility.

\section{REFERENCES}

[1] Black, F. Studies of stock price volatility changes. Proceedings of the 1976 Meetings of the American Statistical Association, Business and Economical Statistics Section, (1976), pp. 177- 181.

[2] Bollerslev, T., R. Engle, \& D. Nelson. ARCH Models in Handbook of Econometrics, ed. by R. Engle, and D. McFadden, North Holland Press, Amsterdam, (1994) chap. 4, pp. 2959-3038.

[3] Campbell, J.Y. \& Hentschel, L. No news is good news: an asymmetric model of changing volatility in stock returns. Journal of Financial Economics, (1992), 31, 281-318.

[4] [4] Cox, J.C.\& Ross, S.A. The valuation of options for alternative stochastic processes. Journal of Financial Economics, (1976), 3, 145166.

[5] Engle, R.F.\& Ng, V.K. Measuring and testing the impact of news on volatility. Journal of Finance, (1993), 48, 1749-1778.

[6] [6] French, K.R., G. W. Schwert, \& R. F. Stambaugh. Expected Stock Returns and Volatility. Journal of Financial Economics, (1987), 19, 3-30.

[7] Friedmann, R. \& Sanddorf-Köhle, W.G. Volatility clustering and non-trading days in Chinese stock markets. Journal of Economics and Business, (2002), 54, 193-217.

[8] Glosten, L.R., Jagannathan, R., Runkle, D.E. On the relation between the expected value and the volatility of the nominal excess return on stocks. Journal of Finance,(1993), 48, 1779- 1801.

[9] Harvey, C. \& Siddique, A.. Autoregressive conditional skewness. Journal of Financial and Quantitative Analysis, (1999), 34, 465-487.

[10] Henry, O. Modelling the asymmetry of stock market volatility. Applied Financial Economics, (1998), 8, 145-153.

[11] Nelson, D.B. Conditional heteroskedasticity in asset returns: a new approach. Econometrica, (1991), 59, 347-370.

[12] Pagan, A.R.\& Schwert, G.W. Alternative models for conditional stock volatility. Journal of Econometrics, (1990), 45, 267-290.

[13] Pindyck, R.S. Risk, inflation, and the stock market. American Economic Review, (1984), 74, 334- 351.

[14] Schwert, G.W. Why does stock market volatility change over time? Journal of Finance, (1989), 44, 1115-1153. 